\title{
Effects of Coastal Groundwater Level on Beach Deformation
}

\author{
Woo-Dong Lee $\circledR^{\circledR}$ and Dong-Soo Hur $\unrhd^{*}$ \\ "Department of Ocean Civil Engineering, Gyeongsang National University, Tongyeong, Korea \\ 해안지하수위가 해빈변형에 미치는 영향 \\ 이우동* - 허동수『* \\ *국립경상대학교 해양토목공학과
}

KEY WORDS: Beach deformation 해빈변형, Beach erosion 해안침식, Swash zone 포말대, Surf zone 쇄파대, Coastal groundwater 해안지 하수, Wave uprush-backwash 처오름과 처내림

\begin{abstract}
In order to understand the characteristics of beach deformation, in this study, numerical simulations were conducted using a 3-D hydro-morphodynamic model (HYMO-WASS-3D) to analyze the characteristics of beach deformation due to the coastal groundwater levels. HYMO-WASS-3D directly analyzed the nonlinear interaction between the hydrodynamic and morphodynamic processes in the coastal area. The simulation results of HYMO-WASS-3D showed good agreement with the experimental results on the changes in the profile of the beach in the surf and swash zones. Then, numerical simulations were conducted to examine the characteristics of beach deformation due to the variation of the level of the coastal groundwater. As a result, the beach profiles were examined in relation to the wave breaking in the surf zone and the wave uprush and backwash in the swash zone due to the differences in the water levels. This paper also discussed the temporal and spatial distributions of the velocities, vorticities, and suspended sediments in the surf and swash zones with various levels of the coastal groundwater.
\end{abstract}

\section{1. 서 론}

해빈은 해양물리력, 특히 파랑으로부터 우리해안을 보호하는 완충지이다. 해빈에서는 쇄파유도, 저면 마찰, 투수성 등에 의해 파랑에너지 소산이 발생하고, 파랑에 의한 처오름, 월파, 침수 등을 크게 감소시킨다. 그 뿐 아니라, 생태적 기능 및 친수 공간 을 제공함으로 해빈은 환경보전과 재해저감에 있어서 매우 중 요한 역할을 한다. 수심이 깊은 해빈은 파랑의 영향을 거의 받 지 않지만, 이동한계수심(Closure depth) 이하에서는 수심이 얕 아질수록 해빈변형이 왕성하다. 연안표사는 주로 쇄파대에서 발생하지만, 파랑에 의한 해빈변형은 포말대에서 가장 활발하 다(Kraus et al., 1982). 특히 포말대의 해변표면에서의 침투 및 유출 흐름은 침 - 퇴적 과정에 큰 영향을 미친다(Nielsen et al., 2001). 다시 말해 해안지하수 흐름이 해빈의 침 - 퇴적 과정에 영향을 미친다는 애기이기도 하다. 해안지하수의 수위는 조석 으로 인해 해수위와 차가 발생하며, 이 수위차는 파랑작용에 의 한 해변표면의 침투/유출유속을 변화시킬 수 있다. 특히 간조 시의 지하수위-해수위 차에 의한 지하수 유출은 침식을 증가시 킨다. 반대로 만조 시에서는 지하수위가 해수위보다 낮아 해수
침투에 의한 퇴적이 유도된다.

이상에 착안하여 고파랑에 의한 급격한 침식을 저감시켜 해 빈 안전을 도모하기 위해 지하수위를 낮출 수 있는 공법이 제 안되었다. 해안지하수위를 하강시키기 위한 양수법과 투수층 매설공법이 대표적이다. 투수층 매설공법에 대해서는 수리모형 실험(Kanazawa et al., 1996), 수치해석(Hur et al., 2012a), 현장실 험(Katoh and Yanagishima, 1996)을 통해 확인된 바 있다. 이로 인해 정선부근의 해안지하수위가 낮아진다면, 해빈의 불포화 영역이 증가하게 된다. 그 영향으로 파랑 처오름이 처내리지 못 하고, 침투로 이어져 소상한 퇴적물이 그대로 해빈에 남는다.

해빈변형은 연안표사와 이안표사로 구분되며, 고파랑에 의한 단기적 변형은 이안표사가 주요 원인이다. 본 연구에서는 고파 랑 조건에서 지하수위가 해빈변형에 미치는 영향을 수치해석을 통해 분석하고자 한다. 수치해석에는 Lee and Hur(2014a)가 개 발한 HYMO-WASS-3D를 이용한다.

\section{2. 수치해석방법}

HYMO-WASS-3D(Lee and Hur, 2014a)는 파동장 모델과 지형

Received 4 October 2019, revised 11 November 2019, accepted 27 November 2019

Corresponding author Dong-Soo Hur: +82-55-772-9122, dshur@gnu.ac.kr ORCID: http://orcid.org/0000-0003-4627-7593

(c) 2019, The Korean Society of Ocean Engineers

This is an open access article distributed under the terms of the creative commons attribution non-commercial license (http://creativecommons.org/licenses/by-nc/3.0) which permits unrestricted non-commercial use, distribution, and reproduction in any medium, provided the original work is properly cited. 
변동 모델이 양방향으로 결합된 3차원 수치모델이며, 유체-해빈 비선형 상호작용에 따른 소류사 및 부유사 거동을 직접 모의할 수 있다.

\section{1 파동장 모델}

파동장 모델은 Hur et al.(2012b), Hur et al.(2012c)과 Lee and $\operatorname{Hur}(2014 b)$ 를 토대로 파랑-해빈-구조물 상호작용에 따른 유체운 동을 해석할 수 있게 개량된 3-D Navier-Stokes(N-S) Solver이다. Large eddy simulation(Smagorinsky, 1963)에 기초한 동적 와동점 성모델(Germano et al., 1991; Lilly, 1992), 표면장력을 정량적으 로 산정할 수 있는 Continuum surface force(CSF) 모델(Brackbill et al., 1992)을 채택하고 있다.

\subsection{1 지배방정식}

파동장 모델의 지배방정식은 다음과 같으며, 해빈, 해저지반, 투수성 방파제 등과 같은 투수매체 내의 유동까지 계산하기 위 해 개량된 연속방정식 (1)과 N-S 운동량 방정식 (2)로 구성된다.

$$
\begin{aligned}
& \frac{\partial\left(\gamma_{i} v_{i}\right)}{\partial x_{i}}=q^{*} \\
& \frac{\partial\left(\gamma_{v} v_{i}\right)}{\partial t}+\frac{\partial\left(\gamma_{i} v_{i} v_{j}\right)}{\partial x_{j}}=-\frac{\gamma_{v}}{\rho_{m}} \frac{\partial p}{\partial x_{i}}+\frac{\partial\left(\gamma_{i} \nu_{T} D_{i j}\right)}{\partial x_{j}}+S_{i}-Q_{i}-R_{i}-\gamma_{v} g_{i}-E_{i}
\end{aligned}
$$

여기서 $v_{i}$ 는 $x, y, z$ 방향의 유속, $q^{*}$ 는 원천의 유량밀도, $\gamma_{v}$ 는 체 적 공극율, $\gamma_{i}$ 는 $x, y, z$ 방향의 면적 공극율, $t$ 는 시간, $\rho_{m}$ 는 부 유사를 고려한 물 밀도, $p$ 는 압력, $\nu_{T}$ 는 부유사를 고려한 물의 동점성계수 $\left(\nu_{m}\right)$ 와 와동점성계수 $\left(\nu_{t}\right)$ 의 합, $D_{i j}$ 는 변형률 속도텐 서, $S_{i}$ 는 $\mathrm{CSF}$ 모델을 기반으로 한 표면장력항, $Q_{i}$ 는 파랑의 생성 과 소멸항, $R_{i}$ 는 투과성 매체에 의한 유체저항항, $g_{i}$ 는 중력가속 도항, $E_{i}$ 는 에너지 감쇠항을 나타낸다.

쇄파처럼 복잡한 자유수면 모의를 위해 식 (3)과 같은 Volume of fluid(VOF)의 이류함수(Hirt and Nichols, 1981)를 이용한다. 연 속방정식 (1)에 비압축성 유체에 대한 가정과 투수매체의 공극 율을 적용하여 유체의 체적보전 형식을 가진다.

$$
\gamma_{v} \frac{\partial F}{\partial t}+\gamma_{i} v_{i} \frac{\partial F}{\partial x_{i}}=F_{q}^{*}
$$

여기서 $F$ 는 각 격자의 유체 체적비이고, $F=1$ 는 물, $F=0$ 는 공 기, $0<F<1$ 는 자유수면을 각각 나타낸다.

투수매체에 의한 유체저항, 난류모델, 표면장력 등에 관한 설 명은 Lee and Hur(2014a)와 Lee and Hur(2014b)를 참고할 수 있다.

\section{2 지형변동 모델}

본 연구의 지형변동 모델은 Hur and Lee(2014a)에 의해 개발 된 것으로 유체운동에 따른 소류사와 부유사의 이동량으로부터 지반높이를 계산할 수 있다.

2.2.1 소류사의 산정

소류사의 이동량은 van Rijn(1984a)의 경험식 (4)를 이용하며,
Shields수가 한계 Shields수를 초과할 경우만 이동량이 발생한다.

$$
S_{b}= \begin{cases}A_{b} \frac{\left\{(s-1) g d_{p}^{3}\right\}^{1 / 2}}{D_{*}^{0.3}}\left(\frac{\theta}{\theta_{c r}}-1\right)^{0.21} & : \theta>\theta_{c r} \\ 0 & : \theta \leq \theta_{c r}\end{cases}
$$

여기서 $A_{b}$ 는 경험상수 $(=0.053), s$ 는 소류사 비중 $\left(s=\rho_{s} / \rho_{f} ; \rho_{s}\right.$ 는 소류사 밀도, $\rho_{f}$ 는 유체 밀도), $\theta$ 는 Shields수 $\left(=\frac{V_{f}^{2}}{(s-1) g d_{p}}\right), \theta_{c r}$ 은 한계 Shields수, $d_{p}$ 는 평균입경, $D_{*}$ 는 무차원 입경 매개변수, $g$ 는 중력가속도, $V_{f}$ 는 전단유속을 각각 나타낸다.

\subsection{2 부유사 산정}

부유사의 거동은 van Rijn(1984b)의 기본개념을 적용하여 퇴 적물의 부유 및 침강에 관한 생성과 소멸항 $\left(Q_{s s}\right)$ 이 포함된 3 차 원 이류-확산 방정식 (5)을 이용하여 추정한다.

$$
\frac{\partial C}{\partial t}+u \frac{\partial C}{\partial x}+v \frac{\partial C}{\partial x}+\left(w-w_{s}\right) \frac{\partial C}{\partial z}-\epsilon_{h} \frac{\partial^{2} C}{\partial x^{2}}-\epsilon_{h} \frac{\partial^{2} C}{\partial y^{2}}-\epsilon_{z} \frac{\partial^{2} C}{\partial z^{2}}=Q_{s s}
$$

여기서 $u, v, w$ 는 각 격자의 $x, y, z$ 방향의 유속성분, $w_{s}$ 는 부유 사의 침강속도, $\epsilon_{h}$ 와 $\epsilon_{v}$ 는 수평과 연직방향의 부유사 혼합계수, $Q_{s s}$ 는 퇴적물의 부유-침강에 따른 부유사의 생성/소멸항이다.

\section{3. 연성해석}

\subsection{1 해빈변형}

지형변동 모델로부터 산정된 소류사 이동량, 퇴적물의 부유침강에 따른 지반고 변화량을 식 (6)에 대입하여 매시간 변화하 는 해빈단면을 추정한다.

$$
\frac{\partial z_{b}}{\partial t}+\frac{1}{1-\gamma_{v}}\left(\frac{\partial S_{b x}}{\partial x}+\frac{\partial S_{b y}}{\partial y}+\Delta z_{s}\right)=0
$$

여기서 $z_{b}$ 는 해빈 높이, $\gamma_{v}$ 는 지반의 체적 공극률, $S_{b x}$ 와 $S_{b y}$ 는 $x$ 와 $y$ 방향의 소류사 이동량, $\Delta z_{s}$ 는 퇴적물의 침강과 부유에 따 른 지반높이 변화이다.

\subsection{2 공극율 산정}

계산시간마다 지형변동 모델에서 산정된 해빈 높이 변화를 파 동장 모델에 적용한다. 본 연구에서는 Lee and Hur(2014a)가 제 안한 해빈 높이에 따른 체적 공극율 $\left(\gamma_{v}\right)$ 을 산정할 수 있는 식 (7) 을 이용한다. 해빈 높이 변화에 따른 $\gamma_{v}$ 은 경사면처리법(Hur et al., 2008)을 적용한 면적투과율 $\left(\gamma_{i}\right)$ 은 파동장 모델에 적용된다.

$$
\left(\gamma_{v}\right)_{k}= \begin{cases}1 & :\left(z_{b}\right)_{k}=0 \\ 1-\frac{\left(z_{b}\right)_{k}}{\Delta z_{k}}\left(1-\gamma_{0}\right) & : 0<\left(z_{b}\right)_{k}<\Delta z_{k} \\ \gamma_{0} & :\left(z_{b}\right)_{k}=\Delta z_{k}\end{cases}
$$

여기서 $\Delta z_{k}$ 는 연직 격자 크기, $\left(z_{b}\right)_{k}$ 는 해빈 높이, $\gamma_{0}$ 는 해빈의 
초기공극율, $\left(z_{b}\right)_{k}=0$ 는 유체 격자, $0<\left(z_{b}\right)_{k}<\Delta z_{k}$ 는 해빈표면 격자, $\left(z_{b}\right)_{k}=\Delta z_{k}$ 는 해빈격자를 각각 나타낸다.

\subsection{3 상태방정식}

부유사는 물의 밀도를 증가시킨다. 본 연구에서는 이류-확산 방정식 (5)에서 얻은 농도(C)를 Ford and Johnson(1986)의 산정 식 (8)에 대입하여 $\rho_{m}$ 을 산정한다.

$$
\rho_{m}=\rho_{f}+C \rho_{f}\left\{1-\frac{1}{\left(\rho_{s} / \rho_{f}\right)}\right\}
$$

여기서 $\rho_{s}$ 는 퇴적물 밀도이다.

부유사에 따른 물의 동점성계수는 Bagnold(1954)의 실험식 (9) 를 통해 $\nu_{m}$ 을 산정한다.

$$
\nu_{m}=\nu_{f}\left(1-\lambda_{c}\right)\left(1-0.5 \lambda_{c}\right)
$$

여기서 $\lambda_{c}$ 는 부유사 농도에 관한 무차원 매개변수이며, 0.13-0.62 범위이고, 0.13 이하는 영향을 고려하지 않는다.

\section{4 수치모델 검증}

수치모델 검증에는 Choi et al.(2016)이 한국건설기술연구소 실험수조에서 해운대해수욕장의 현장조건을 고려하여 수행한 수 리모형실험을 이용한다. Fig. 1처럼 길이 $48 \mathrm{~m}$, 폭 $1 \mathrm{~m}$, 높이 $2 \mathrm{~m}$
Table 1 The experimental conditions used in Choi et al.(2016)

\begin{tabular}{cccc}
\hline \hline & Model & Prototype & Note \\
\hline$H_{i}[\mathrm{~m}]$ & 0.1 & 1 & \\
$T_{i}[\mathrm{~s}]$ & 2 & 6.3 & Normal wave \\
$d_{50}[\mathrm{~mm}]$ & 0.18 & 0.4 & Sediment \\
\hline
\end{tabular}

의 2 차원 파동수조에는 $1: 25$ 경사의 수중 해빈과 $1: 12.5$ 경사의 육상 해빈이 배치되었다. 본 수치모델 검증에는 평상파랑조건 만 고려하였으며, Choi et al.(2016)이 제시한 현장조건과 모형실 험조건은 Table 1 과 같다.

Fig. 2는 120 분 동안 평상파랑이 지속 작용하여 초기 해빈단 면이 변형된 것이며, 해빈표면의 붉은색은 부유사를 나타낸다.

외해에서 유입된 파랑이 수심변화에 따른 천수효과에 의해 파장이 짧아지고, 파고가 상승하는 현상을 Fig. 2의 파동장으로 부터 확인할 수 있다. 그리고 쇄파대에서는 해빈표면에서 부유 사가 발생하고, 침식작용에 의해 소단이 형성된다. 이 연성해석 을 통해 얻어진 해빈단면을 실험에서 측정한 값과 비교하면, Fig. 3과 같다.

Fig. 3에서 나타나듯이 외해와 정선 부근의 해빈침식을 계산값 이 실험값을 조금 과소평가 하고 있지만, 해빈의 전반적인 침 - 퇴 적 양상을 잘 재현하고 있다. 이로써 해빈 단면변형 수치모의에 있어서 본 연구에서 적용하는 연성모델(HYMO-WASS-3D; Lee and Hur, 2014a)의 타당성과 유효성이 검증되었다고 판단된다.

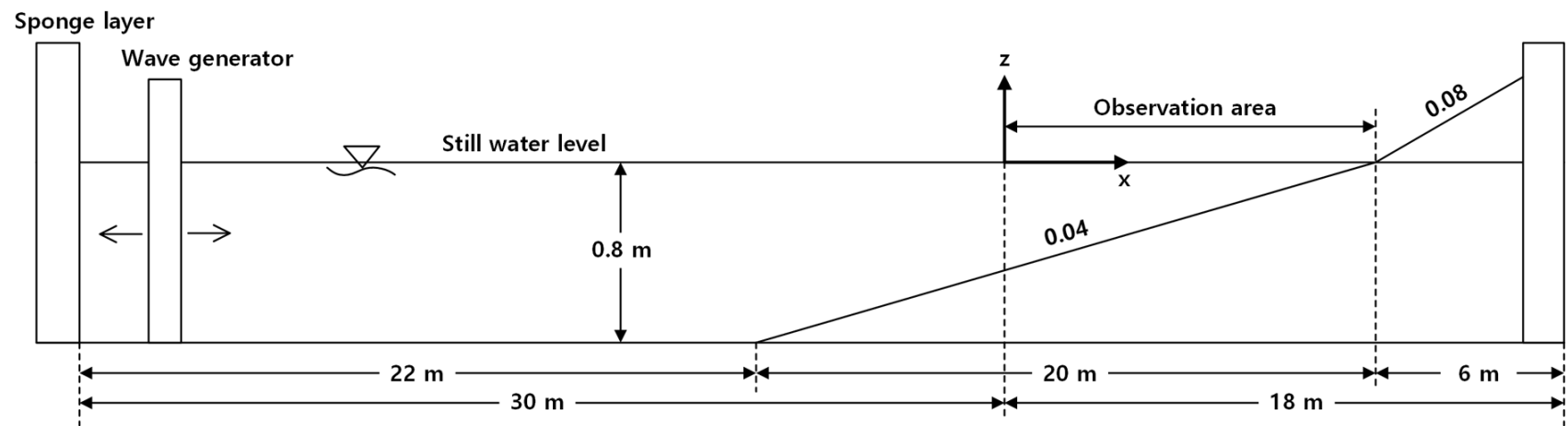

Fig. 1 Sketch of experimental set-up and initial beach profile (Choi et al., 2016)

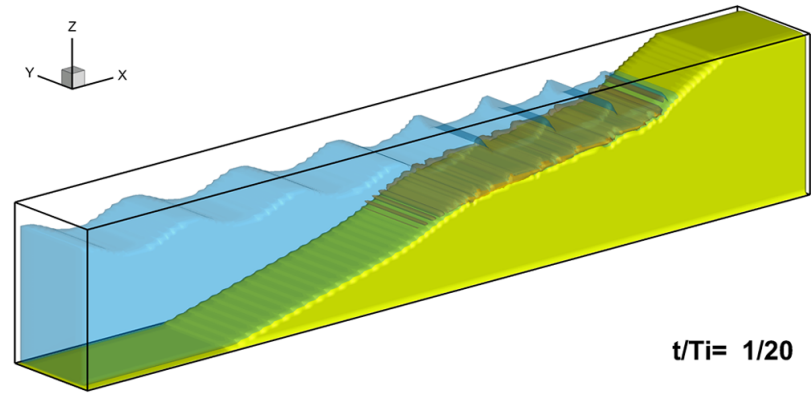

Fig. 2 Numerical result of hydro-morphodynamic model (HYMOWASS-3D)

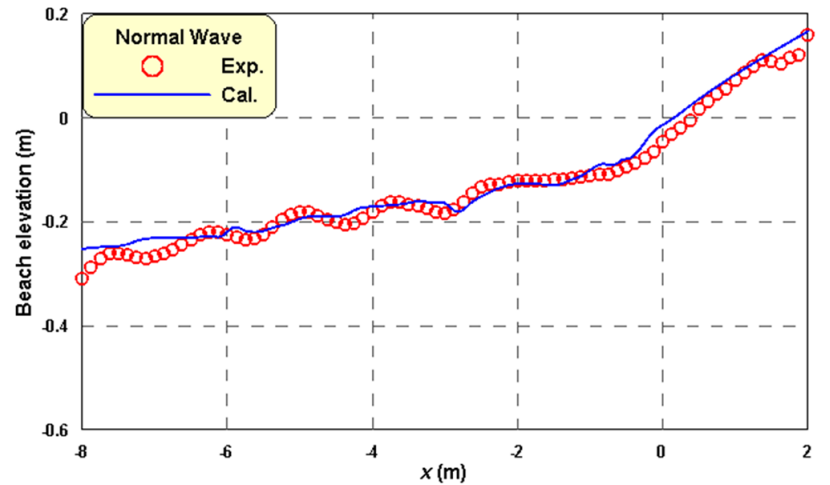

Fig. 3 Comparison between measured and simulated equilibrium beach profiles 


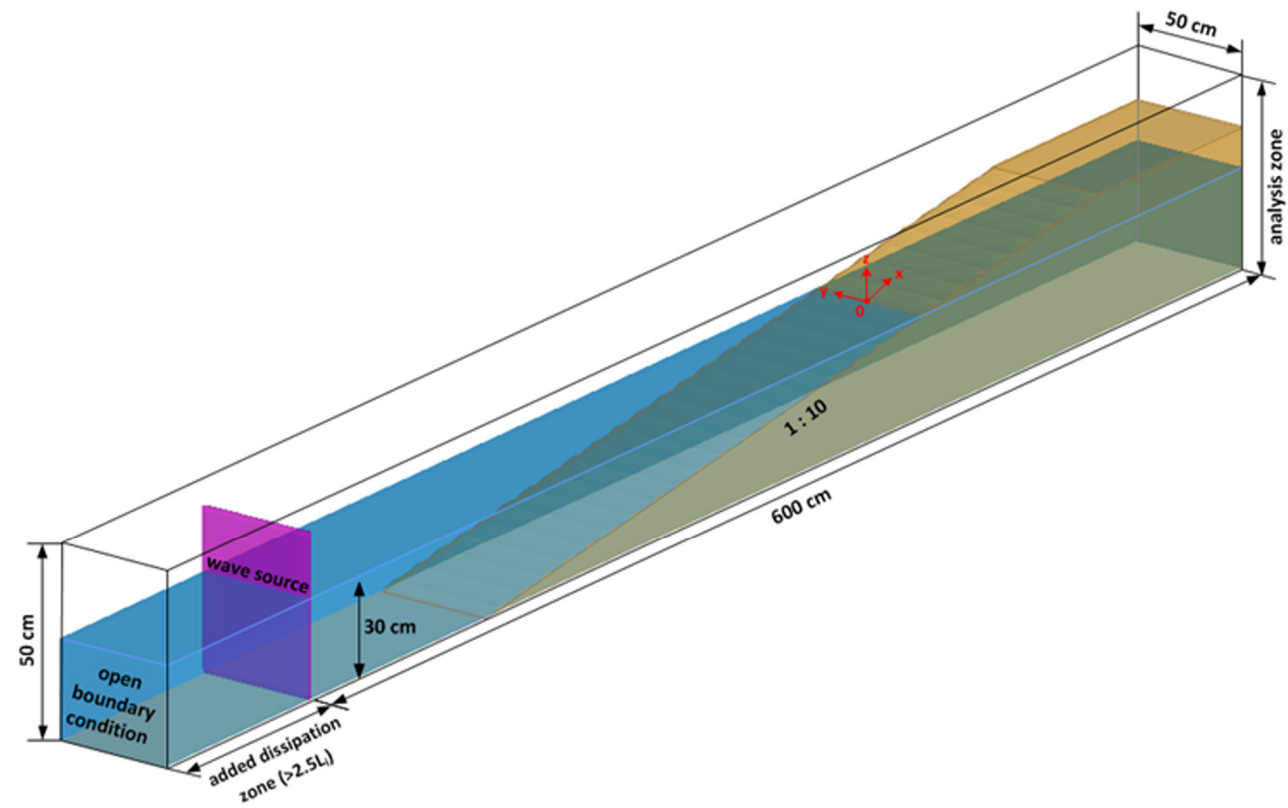

Fig. 4 Definition sketch of 3-D numerical wave tank including sandy beach

\section{5 수치해석조건}

해안지하수위에 따른 해빈변형 특성을 수치적으로 분석하기 위하여 Fig. 4 와 같은 길이 $600 \mathrm{~cm}$, 폭 $50 \mathrm{~cm}$, 높이 $60 \mathrm{~cm}$ 의 3 차원 수치파동수조를 구성한다. 수심 $(h) 30 \mathrm{~cm}$ 의 해석영역에는 평균 입경 $\left(d_{p}\right) 0.1 \mathrm{~mm}$, 체적공극율 $\left(\gamma_{v}\right) 0.4$, 경사 $1: 10$ 의 해빈을 설치한 다. 그리고 해석영역은 수평방향 $1 \mathrm{~cm}$, 수직방향 $0.25 \mathrm{~cm}$ 로 등분 할한다. 초기 해안지하수위 $\left(h_{g}\right)$ 는 $h$ 보다 같거나 높으며, 수위차 $(\Delta h)$ 는 $0 \mathrm{~cm}, 1 \mathrm{~cm}, 2 \mathrm{~cm}, 3 \mathrm{~cm}, 4 \mathrm{~cm}, 5 \mathrm{~cm}$ 로 총 6 가지이다. 장시간 조파에 따른 파동장 교란을 방지하기 위해 외해에는 부가감쇠 영역, 개경계조건, 조파소스로 구성된 무반사 조파시스템을 적 용한다. 바닥경계조건은 Non-slip, 측면경계조건은 Slip조건을 각 각 적용한다.

파랑조건에 따른 해빈변형 영향을 배제하기 위해 입사파랑은 파고 $\left(H_{i}\right) 8 \mathrm{~cm}$, 주기 $\left(T_{i}\right) 1.2$ 초로 고정한다. 상세한 수치해석조건 은 Table 2 와 같다. 입사파랑조건에 따른 강한 쇄파를 감안하여 초기 계산시간간격은 $1 / 500$ 초로 설정하며, 수치해석 안정조건을 만족할 수 있게 계산시간마다 자동 조절된다. 총 계산시간은 20 분이며, 수치파동수조에서 1,000 개 파랑을 발생시킨다.

Table 2 Incident wave and depth conditions used in this study

\begin{tabular}{|c|c|c|c|c|c|c|}
\hline \multirow[b]{2}{*}{ Case } & \multicolumn{2}{|c|}{ Wave } & \multirow[b]{2}{*}{$\begin{array}{l}\text { Water depth, } \\
\quad h[\mathrm{~cm}]\end{array}$} & \multirow[b]{2}{*}{$\begin{array}{l}\text { Groundwater depth, } \\
h_{g}[\mathrm{~cm}]\end{array}$} & \multirow[b]{2}{*}{$\begin{array}{c}\Delta h \\
{[\mathrm{~cm}]}\end{array}$} & \multirow[b]{2}{*}{$\Delta h / h$} \\
\hline & $\begin{array}{c}H_{i} \\
{[\mathrm{~cm}]}\end{array}$ & $\begin{array}{r}T_{i} \\
{[\mathrm{~s}]}\end{array}$ & & & & \\
\hline 0 & \multirow{6}{*}{8} & \multirow{6}{*}{1.2} & \multirow{6}{*}{30} & 30 & 0 & 0 \\
\hline 1 & & & & 31 & 1 & 0.033 \\
\hline 2 & & & & 32 & 2 & 0.067 \\
\hline 3 & & & & 33 & 3 & 0.1 \\
\hline 4 & & & & 34 & 4 & 0.133 \\
\hline 5 & & & & 35 & 5 & 0.167 \\
\hline
\end{tabular}

\section{3. 수리특성}

지하수위가 해빈변형에 미치는 영향을 분석하기 위해 수리현 상에 대해 먼저 논의한다. 여기서는 대표적으로 해수위-지하수 위 차가 없는 경우 $(\Delta h / h=0)$, 해수위-지하수위 차가 가장 큰 경 우의 수리특성을 비교 · 분석한다.

\section{1 파동/유동/와동장}

Fig. 5는 파랑작용 하에서 $x-z$ 중앙 단면의 파동/유동/와동 장이며, $t / T_{i}=4 / 24$ 간격으로 1 주기를 나타낸다. Fig. 5은 쇄파 대와 포말대를 포함하며, $x=500 \mathrm{~cm}$ 지점이 정선이다. Fig. 5(a) 는 해수위-지하수위의 차가 없는 경우 $(\Delta h / h=0)$, Fig. 5(b)는 지 하수위가 해수위보다 높은 경우 $(\Delta h / h=1.67)$ 이다. 그리고 와도 에 있어서 붉은색 계열은 시계방향, 파란색 계열은 반시계 방 향의 와도를 각각 나타내며, Raffel et al.(1998)의 계산식을 적용 하였다.

Fig. 5에서 $t / T_{i}=19 / 24$ 에서 최대 처오름이 발생하고, 지하수 위가 높은 (b) $\Delta h / h=1.67$ 의 처오름이 더 강하게 나타난다. 이 현상은 지하수위가 높을수록 해빈으로 스며든 물의 배수가 원 활하지 않아 후속 처오름이 용이해지기 때문이다. 처내림 역시 지하수위가 높을수록 해빈의 포화시간이 길어짐으로 물이 스며 들지 못하고, 해빈표면을 따라 흘러내리는 것을 $t / T_{i}=21 / 24$ 에 서 확인할 수 있다. 이것에 기인하여 지하수위가 높은 (b) $\Delta h / h=1.67$ 의 경우가 $t / T_{i}=09 / 24$ 에서 더 강한 쇄파가 나타난 다. 또한 유입파와 처내림 흐름의 중첩으로 파고 증가현상이 발 생하기도 한다. 이처럼 쇄파대와 포말대의 역동적인 유동현상 에 의해 해빈표면에서 강한 와도가 형성되고, 지하수위가 높은 (b) $\Delta h / h=1.67$ 에서 더욱 강한 와도가 관찰된다. 이같이 지하수 위에 따른 파동/유동/와동 특성의 차이는 해빈 포화와 지하수 유출이 복합적으로 작용하여 나타난다. 

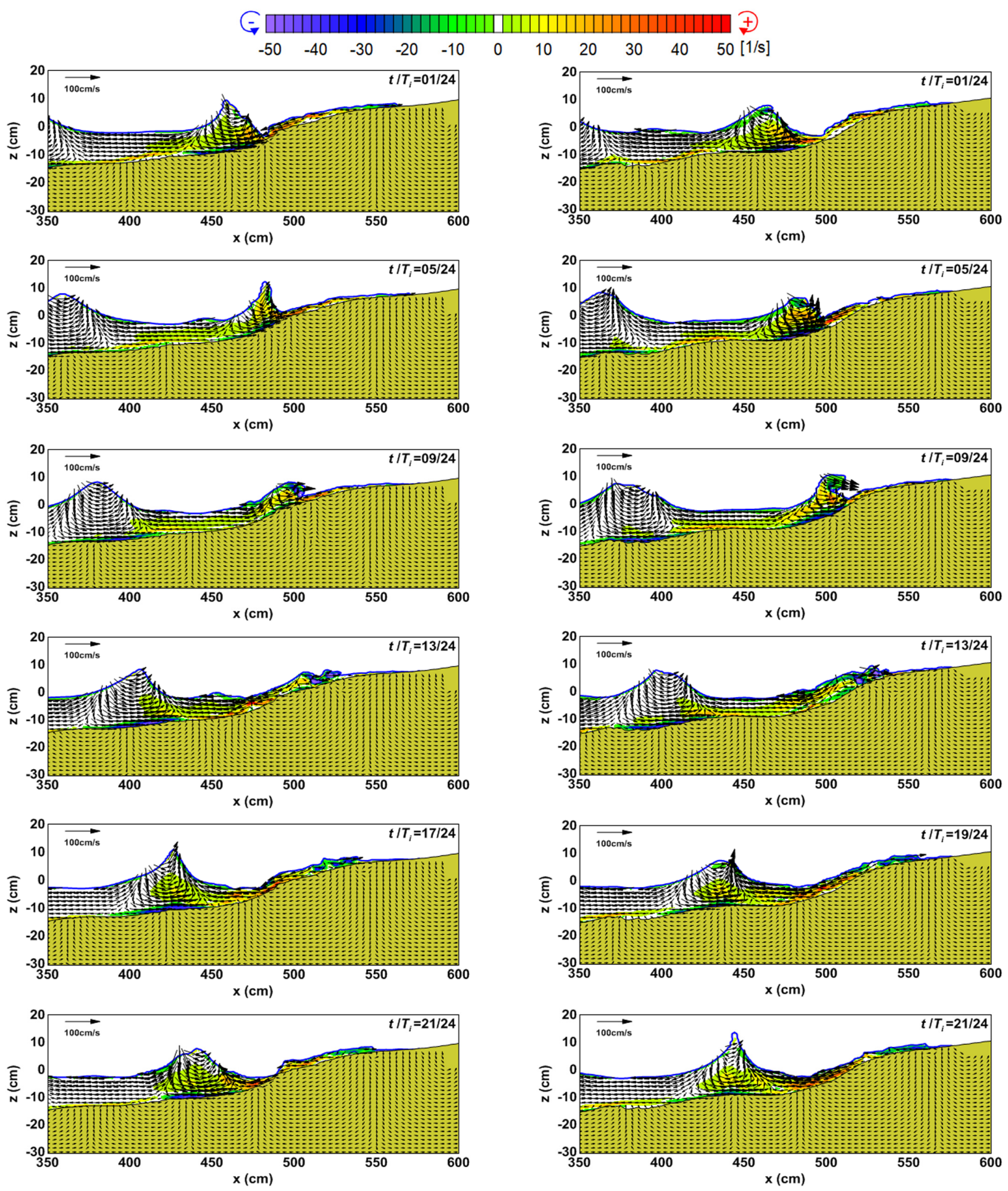

(a) $\Delta h / h=0$

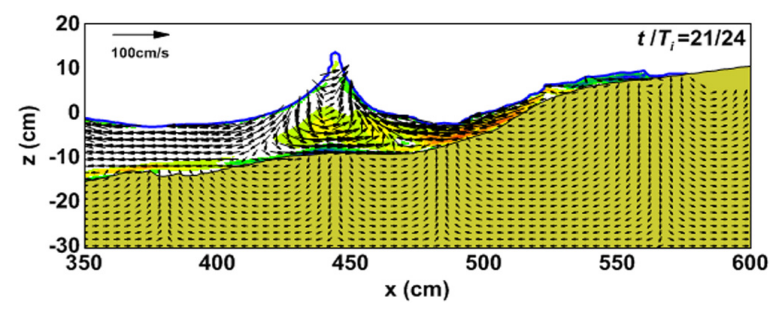

(b) $\Delta h / h=1.67$

Fig. 5 Temporal and spatial characteristics of wave, flow and vortex fields in surf and swash zone

\section{2 파고분포}

Fig. 6과 Fig. 7은 지하수위에 따른 쇄파대와 포말대의 파고분 포, 평균수위분포를 비교한 것이다. 여기서 검정색 삼각형은 해 수위-지하수위의 차가 없는 경우 $(\Delta h / h=0)$, 붉은색 원은 지하수 위가 해수위보다 높은 경우 $(\Delta h / h=1.67)$ 를 각각 나타낸다.

Fig. 2에서 확인한 것처럼 천수효과로 해빈 상의 파고가 입사 파고보다 더 높은 것을 알 수 있다. Fig. 6으로부터 전술과 같이
유입파와 처내림의 강한 중첩이 발생하는 $\Delta h / h=1.67$ 의 파고가 $\Delta h / h=0$ 보다 전반적으로 높다. Fig. 5 에서 확인한 것과 같이 강 한 쇄파가 발생하는 $\Delta h / h=1.67$ 가 쇄파 후, 파고감쇠가 크다. 그 영향으로 Fig. 7에서 확인할 수 있듯이 쇄파지점부터 정선까 지 평균수위 상승이 두드러진다. 특히 해빈으로 지하수 유출이 발생하는 $\Delta h / h=1.67$ 의 평균수위가 더 높다.

전술한 파동/유동/와동장, 파고분포, 평균수위분포의 수리특성 


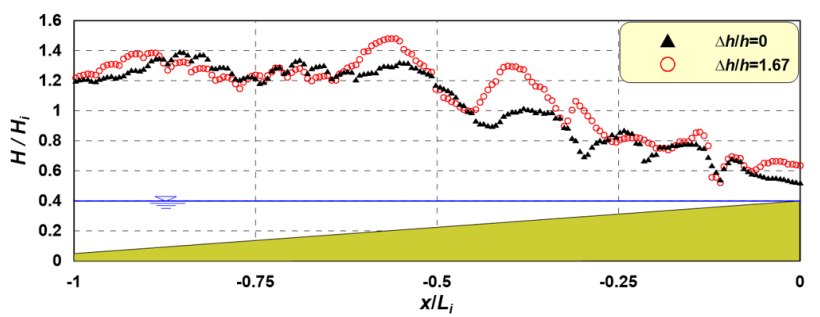

Fig. 6 Comparisons of wave heights due to groundwater level

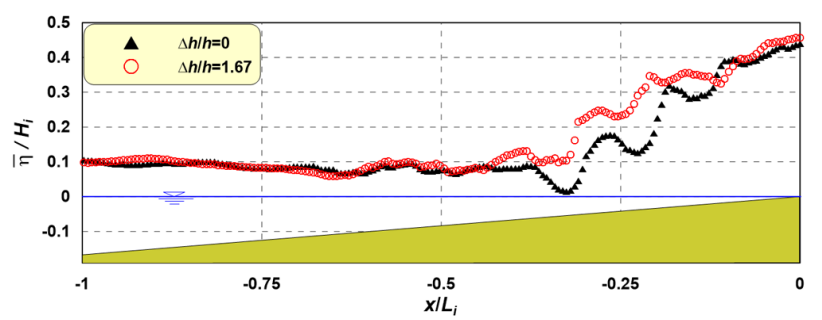

Fig. 7 Comparisons of mean water levels due to groundwater level
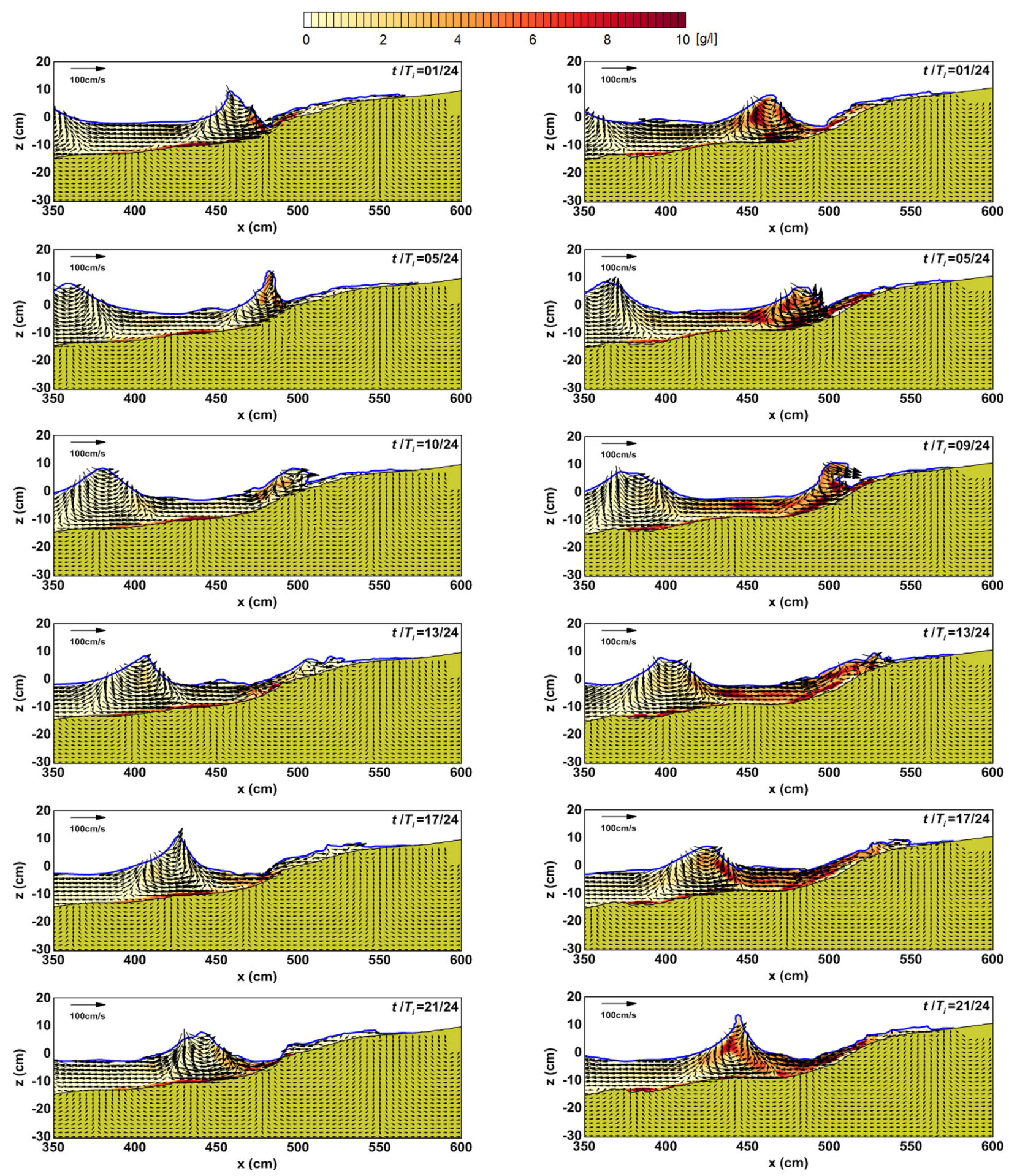

(a) $\Delta h / h=0$

(b) $\Delta h / h=1.67$

Fig. 8 Temporal and spatial distributions of suspended sediments in surf and swash zone 
에 근거하여 지하수위가 해수위보다 높으면, 해빈 포화에 따른 처오름, 처내림이 강해지고, 지하수 유출흐름이 발생한다. 이 현 상은 쇄파대와 포말대의 유체운동을 더욱 복잡하고, 활발하게 만 든다. 결국, 이 유체운동은 해빈 저질이동의 외력으로 작용한다.

\section{4. 지형변동 특성}

3장에서 논의한 해안지하수위에 따른 쇄파대와 포말대의 수 리특성에 기초하여 파랑작용에 의한 해빈변형 메커니즘을 정성 적으로 분석한다.

\section{1 부유사 거동}

Fig. 8은 쇄파대와 포말대에서 파랑작용에 따른 부유사 거동 을 $t / T_{i}=4 / 24$ 간격으로 1 주기 동안 나타낸 것이다. Fig. 8(a)는 해수위-지하수위의 차가 없는 경우 $(\Delta h / h=0)$, Fig. 8(b)는 지하 수위가 해수위보다 높은 경우 $(\Delta h / h=1.67)$ 이다. 여기서 색이 짙 을수록 부유사 농도가 크며, 컬러 스케일로부터 농도를 확인할 수 있다.

Fig. 8로부터 쇄파대보다 포말대에서 부유사 발생이 활발하 다. 특히 쇄파지점의 부유사 농도가 짙고, 처내림에 더 많은 부 유사가 발생한다. 식 (6)에서 알 수 있듯이, 처내림 시의 유속방 향은 하향경사임으로 중력이 가중되어 나타나는 현상으로 이해 된다. 그리고 지하수위가 높은 (b) $\Delta h / h=1.67$ 가 $\Delta h / h=0$ 보다 흐름이 강함으로 전체적인 부유사량이 많다. 또한, 포말대에서 발생한 부유사가 지하수위-해수위 동수경사에 의한 유출흐름에 의해 더 멀리 이동한다.

부유사 거동특성으로부터 해안지하수위가 높을수록 포말대의 부유사 발생량이 증가하고, 쇄파대 쪽으로 더 멀리 이동시킴으 로 해안선 부근의 침식이 증가하는 것으로 판단된다.

\section{2 해빈단면 변화}

Fig. 9는 파랑작용에 따른 쇄파대와 포말대의 해빈 침·퇴적 양상을 비교한 것이며, (a)는 해빈단면, (b)는 해빈의 침·퇴적 높이를 각각 나타낸다. 여기서 검은색 실선은 해수위-지하수위 가 같은 경우 $(\Delta h / h=0)$, 나머지는 지하수위가 해수위보다 높으 며, 파란 점선은 $\Delta h / h=0.033$, 파란 실선은 $\Delta h / h=0.067$, 붉은 점선 $\Delta h / h=0.1$, 붉은 실선은 $\Delta h / h=0.133$, 검정 원은 $\Delta h / h=0.167$ 를 각각 의미한다.

Fig. 9에서는 지속적 파랑운동에 의해 쇄파대의 침식작용 및

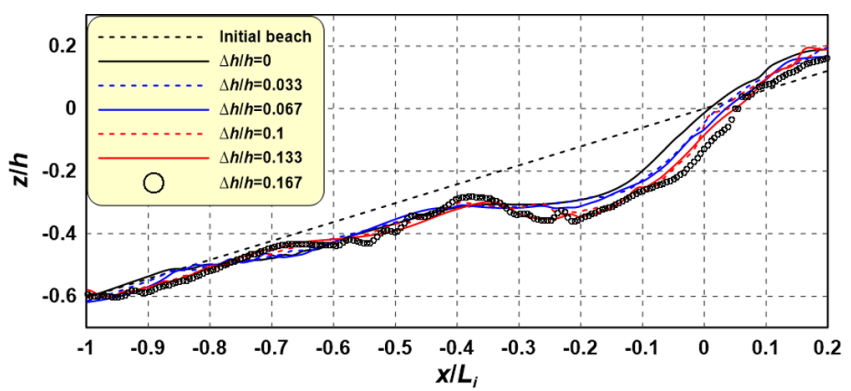

(a) Beach profile
소단 형성, 처오름에 의한 포말대의 퇴적작용이 나타난다. Fig. 5 에서는 $\Delta h / h$ 가 클수록 쇄파대에서는 쇄파가 강하게 발생하고, 포말대에서는 해빈 포화에 따른 파랑의 처오름/처내림이 활발 해진다. 그 영향으로 $\Delta h / h$ 가 클수록 부유사 발생량 뿐만 아니 라, 소류사 이동량 역시 증가한다. 그 결과, 해수위와 지하수위 차가 가장 큰 $\Delta h / h=0.167$ 에서는 쇄파대의 침식작용, $\Delta h / h=0$ 에서는 포말대 상부의 퇴적작용이 두드러진다. 지하수위가 낮 을수록 포말대의 처오름이 처내림으로 이어지지 않고, 해빈으 로 스며들기 때문에 처오름 시에 육상으로 올라간 모래가 내려 오지 않는다. 한편, 해빈 포화에 따른 유체운동이 활발한 $\Delta h / h=0.167$ 는 저질이동이 왕성하여 $x / L_{i}=0.35$ 부근에 사주가 발달한다. 이렇게 형성된 해빈단면은 전형적인 해빈지형 특성 을 잘 보여준다.

\section{3 해안선 후퇴}

지속적 파랑작용은 연안표사를 발생시키고, 그로 인해 해빈단 면과 해안선의 변화가 나타난다. 본 연구의 계산조건, 해안지하 수위에 따른 해안선 후퇴를 Table 3에 나타낸다.

앞선 논의에서 $\Delta h / h$ 가 클수록 쇄파대에서는 침식현상, $\Delta h / h$ 가 작을수록 포말대에서는 퇴적현상이 두드러지게 발생하였다. 그 결과 $\Delta h / h$ 가 클수록 해안선의 후퇴거리가 큰 것을 Table 3 에서 확인할 수 있다. 이것은 포말대에서 처내림 시에는 하향경 사로 유속이 작용함으로 중력이 가중되고(식 (6) 참조), 해빈표 면에서의 지하수 유출유속이 더해짐에 따라 모래를 정선에서부 터 멀리 이동시키기 때문이다. 그 결과, $\Delta h / h$ 가 클수록 해안선 의 후퇴거리는 증가하게 된다.

Table 3 Beach erosions due to groundwater level under wave actions

\begin{tabular}{ccccc}
\hline \hline \multirow{2}{*}{ Case } & \multicolumn{2}{c}{ Wave } & & Retreat distance \\
\cline { 2 - 3 } & $H_{i}[\mathrm{~cm}]$ & $T_{i}[\mathrm{~s}]$ & & $\Delta x / L_{i}$ \\
\hline 0 & & & 0 & 0.019 \\
1 & & & 0.033 & 0.031 \\
2 & & & 0.067 & 0.041 \\
3 & 8 & 1.2 & 0.1 & 0.046 \\
4 & & & 0.133 & 0.057 \\
5 & & & 0.167 & 0.063 \\
\hline
\end{tabular}

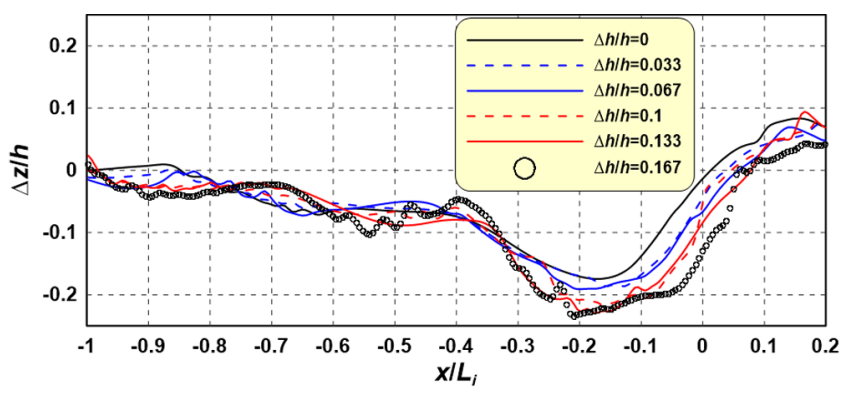

(b) Beach erosion and deposition

Fig. 9 Comparisons of beach deformations due to groundewater level in surf and swash zone 


\section{5. 결론 및 고찰}

본 연구에서는 3 차원 연성모델을 적용한 수치모의를 통해 해 안지하수위에 따른 해빈변형 특성을 정성적으로 조사하였다. 먼저, 연성모델의 타당성과 수치모의결과의 유효성을 입증할 목적으로 Choi et al.(2016)의 이동상 실험결과와 계산결과를 비 교하였다. 해운대해수욕장의 평상파 및 지질조건을 고려한 계 산결과가 실험결과를 잘 재현하였다. 검증된 3 차원 연성모델을 이용한 수치모의결과로부터 해안지하수위가 쇄파대와 포말대의 수리현상 및 해빈변형에 미치는 영향을 분석하였으며, 주요한 결과는 다음과 같다.

(1) 포말대에서는 해안지하수위가 높을수록 해빈의 포화시간 이 길어져 파랑의 처오름/처내림 현상이 활발하게 나타났다.

(2) 쇄파대에서는 입사파와 지하수 유출흐름이 중첩되어 파고 및 평균수위가 증가하는 경향을 나타내었다.

(3) 해안지하수위가 높을수록 쇄파대 및 포말대에서 역동적이 고, 활발한 유체운동이 나타나고, 이로 인해 해빈표면 부근에서 강한 와도가 형성되었다.

(4) 해안지하수위가 높을수록 해빈 상의 파랑 처오름/처내림 이 용이함으로 해빈표면의 부유사 발생이 포말대에서 증가하였 다. 그리고 지하수 유출흐름의 영향으로 부유사가 정선으로부 터 멀리 확산되는 경향을 나타냈었다.

(5) 처내림의 유속방향은 하향경사임으로 중력이 가중되어 이 안표사가 발생하였다. 해안지하수위가 높을수록 처내림이 강해져 포말대의 침식이 심해지고, 해안선의 후퇴거리가 증가하였다.

(6) 쇄파대에서는 쇄파에 기인한 침식현상 및 소단 형성은 해 안지하수위가 높을수록 쇄파가 강하게 발생하는 관계로 더욱 두드러지는 경향을 나타내었다.

(7) 해안지하수위가 낮을수록 파랑 처오름이 처내림으로 이어 지지 못하고, 해빈으로 스며들기 때문에 포말대 상부로 이동한 모래의 퇴적작용이 우세하게 나타났다. 그 결과, 해안선의 변화 는 크게 나타나지 않는다.

본 연구결과를 종합하면, 해안지하수가 해빈변형에 미치는 영 향이 크며, 지하수 제어를 통한 연안침식저감이 가능할 것으로 판단된다.

본 연구에서 3 차원 연성모델을 적용하여 해안지하수위가 해 빈변형에 미치는 영향에 대한 정성적 논의만 수행하였다. 향후, 이 연성모델을 다각도에서 타당성 및 유효성을 검증하고, 다양 한 파랑/흐름조건, 해안구조물 설치에 따른 해빈변형 특성을 정 량적으로 분석할 계획이다. 특히, 대형수조에서 수행한 수리실 험과 연계하여 유속, 해빈단면, 부유사 농도, 처오름 등을 비교 - 검토한다.

\section{후 기}

이 논문은 2018년 해양수산부 재원으로 해양수산과학기술진 흥원의 지원을 받아 수행된 연구임(연안침식 관리 및 대응기술 실용화).

이 성과는 2018년도 정부(과학기술정보통신부)의 재원으로 한 국연구재단의 지원을 받아 수행된 연구임(No. NRF-2018R1C1B 6007461).

\section{References}

Bagnold, R.A., 1954. Experiments on a Gravity-Free Dispersion of Large Solid Spheres in a Newtonian Fluid under Shear. Proceedings of the Royal Society of London, 225(1160), 49-63. https://doi.org/10.1098/rspa.1954.0186

Brackbill, J.U., Kothe, D.B., Zemach, C., 1992. A Continuum Model for Modeling Surface Tension. Journal of Computational Physics, 100(2), 335-354. https://doi.org/10.1016/0021-9991(92)90240-Y

Choi, J., Roh, M., Kim, Y.T., 2016. A Laboratory Experiment on Beach Profile Evolution Induced by Two Wave Conditions Dominated in the Haeundae Coast of Korea. Journal of Coastal Research, SI 75, 1327-1331. https://doi.org/10.2112/SI75-266.1

Ford, D.E., Johnson, L.S., 1986. An Assessment of Reservoir Mixing Process. Technical Report E-86-7, U.S. Army Engineer Waterways Experiment Station, Vicksburg.

Germano, M., Piomelli, U., Moin, P., Cabot, W.H., 1991. A Dynamic Subgrid-Scale Eddy Viscosity Model. Physics of Fluids, 3, 1760-1765. https://doi.org/10.1063/1.857955

Hirt, C.W., Nichols, B.D., 1981. Volume of Fluid (VOF) Method for the Dynamics of Free Boundaries. Journal of Computational Physics, 39(1), 201-225. https://doi.org/10.1016/0021-9991(81) 90145-5

Hur, D.S., Lee, W.D., Bae, K.S., 2008. On Reasonable Boundary Condition for Inclined Seabed/Structure in Case of the Numerical Model with Quadrilateral Mesh System. Journal of The Korean Society of Civil Engineers, 28(5B), 591-594.

Hur, D.S., Lee, W.D., Cho, W.C., 2012a. Beach Stabilization by the Laying of a Drainage Layer. Science China Technological Sciences, 55(9), 2625-2639. https://doi.org/10.1007/ s11431-0124886-6

Hur, D.S., Lee, W.D., Cho, W.C., 2012b. Three-Dimensional Flow Characteristics around Permeable Submerged Breakwaters with Open Inlet. Ocean Engineering, 44, 100-116. https://doi.org/ 10.1016/j.oceaneng.2012.01.029

Hur, D.S., Lee, W.D., Cho, W.C., 2012c. Characteristics of Wave Run-Up Height on a Sandy Beach behind Dual-Submerged Breakwaters. Ocean Engineering, 45, 38-55. https://doi.org/10.1016/ j.oceaneng.2012.01.030

Kanazawa, H., Matukawa, F., Katoh, K., Hasegawa, I., 1996. Experimental Study on the Effect of Gravity Drainage System on Beach Stabilization. Proceedings of $25^{\text {th }}$ International Conference on Coastal Engineering, ASCE, 2640-2653. https:// doi.org/10.1061/9780784402429.204

Katoh, K., Yanagishima, S., 1996. Field Experiment on The Effect of Gravity Drainage System on Beach Stabilization. 25th International Conference on Coastal Engineering, ASCE, 2654-2665. https://doi.org/10.1061/9780784402429.205

Kraus, N.C., Isobe, M., Igarashi, H., Sasaki, T., Horikawa, K., 1982. Fields Experiments on Longshore Sand Transport in the Surf Zone. $18^{\text {th }}$ International Conference on Coastal Engineering, 
ASCE, 969-988. https://doi.org/10.1061/9780872623736.061

Lee, W.D., Hur, D.S., 2014a. Development of a 3-D Coupled HydroMorphodynamic Model between Numerical Wave Tank and Morphodynamic Model under Wave-Current Interaction. Journal of the Korean Society of Civil Engineers, 34(5), 1463-1476. https://doi.org/10.12652/Ksce.2014.34.5.1463

Lee, W.D., Hur, D.S., 2014b. Development of 3-D Hydrodynamical Model for Understanding Numerical Analysis of Density Current Due to Salinity and Temperature and its Verification. Journal of the Korean Society of Civil Engineers, 34(3), 859-871. https:// doi.org/10.12652/Ksce.2014.34.3.0859

Lilly, D.K., 1992. A Proposed Modification of the Germano Subgrid-Scale Closure Method. Physics of Fluids, 4(3), 633-635. https://doi.org/10.1063/1.858280

Nielsen, P., Robert, S., Moller-Christiansen, B., Oliva, P., 2001.
Infiltration Effects on Sediment Mobility under Waves. Coastal Engineering, 42(2), 105-114. https://doi.org/10.1016/S0378-3839 (00)00051-X

Raffel, M., Willert, C.E., Kompenhans, J., 1998. Particle Image Velocimetry: A Practical Guide. Springer Verlag, Berlin.

Smagorinsky, J., 1963. General Circulation Experiments with the Primitive Equation: I. The Basic Experimen. Monthly Weather Review, 91(3), 99-164. https://doi.org/10.1175/1520-0493(1963) 091<0099:GCEWTP>2.3.CO;2

van Rijn, L.C., 1984a. Sediment Transport, Part I: Bed Load Transport. Journal of Hydraulic Engineering, 110(10), 1431-1456. https://doi.org/10.1061/(ASCE)0733-9429(1984)110:10(1431)

van Rijn, L.C., 1984b. Sediment Transport, Part II: Suspended Load Transport. Journal of Hydraulic Engineering, 110(11), 1613-1641. https://doi.org/10.1061/(ASCE)0733-9429(1984)110:11(1613) 